\title{
Survey of Climate-Related Risks to Tilapia Pond Farms in Northern Thailand
}

\author{
Pornpimol Pimolrat ${ }^{1}$, Niwooti Whangchai ${ }^{1}$, Chanagun Chitmanat ${ }^{1}$, Jongkon Promya ${ }^{1}$, Louis Lebel $^{2}$ \\ ${ }^{1}$ Faculty of Fisheries Technology and Aquatic Resources, Maejo University, Chiang Mai, Thailand \\ ${ }^{2}$ Unit for Social and Environmental Research (USER) Faculty of Social Science, Chiang Mai University, Chiang Mai, Thailand \\ Email: paqua50@gmail.com
}

Received July 2013

\begin{abstract}
Climate is an important factor for aquaculture production. This study aimed to understand how farmers that culture tilapia in earthen ponds perceive and respond to climate impacts. Important climate-related risks identified include extreme temperatures (hot and cold), excessive rainfall, prolonged cloud cover, flood and drought. Site visits and data collection using questionnaires were conducted to identify important factors influencing farm profits, losses, decision to increase or decrease ponds. Special attention was given to knowledge about fish markets and weather and the impacts of weather and climate on fish growth, disease outbreaks and water quality in ponds. Altogether 585 fish farms in four provinces in northern part of Thailand selected to cover a range of elevations above sea level and thus climate were surveyed (Nakornsawan $<100$ m, Lampang 100 - 300 m, Phayao 300 - 500 m and Chiang Mai $>500$ m). Fish farms at different elevations reported different climate and weather-related impacts. In the area where elevation above sea level is $<100 \mathrm{~m}$, farmers were affected more by floods and extreme hot weather which caused fish deaths and stress that reduced feeding and growth rates. Conversely, fish farmers in the area where elevation above sea level is $>500$ were impacted mainly by drought and cold weather. These conditions also caused disease outbreaks and reduced feeding rates. Farmers responded by reducing the amount of feed supplied and considering non-fish pond or non-farm supplementary occupations as an adaptation strategy. Among non-climate related factors high prices of feed were most commonly identified as a key issue by farmers. The differences among sites at higher and lower elevation provided insights into the kind of changes in risks farmers may face as climate changes that could be helpful in developing adaptation strategies for individual farmers and the sector as a whole.
\end{abstract}

Keywords: Climate; Tilapia Pond Culture; Aquaculture; Thailand

\section{Introduction}

Climate is an environmental factor that is strongly associated to aquaculture productivity [1]. Being coldblooded animal, fish is affected by the temperature of the surrounding water which influences the body temperature, growth rate, food consumption, feed conversion, and other body functions $[2,3]$. Over the past few years, rising global temperatures have received much attention because of their worldwide impact on ecosystems. The climate models referenced by the Intergovernmental Panel on Climate Change (IPCC) [4] predicted that global temperatures are likely to increase by $1.4^{\circ} \mathrm{C}$ to $6.4^{\circ} \mathrm{C}$ in this century.

Nile tilapia (Oreochromis niloticus) is a freshwater fish of great commercial interest. It is easy to culture and adapts well to a range of environments. Tilapia culture is one of the largest aquaculture industries in Thailand [5]. In the mountainous northern region, relatively high altitude and latitude contribute to more pronounced seasonal temperature variation, with cooler winters than in other regions. Numerous climate variables vary with elevation [6].

Some farmers rear fish in cages suspended in rivers. This culture system is sensitive to extreme weather events, such as floods or droughts $[7,8]$. It is also sensitive to seasonal differences in water temperature, flow speeds and water quality. Ponds, however, are the most common production systems on a worldwide basis. Tilapia fish culture in earthen ponds in northern Thailand can be divided into three categories: commercial, integrated (with pig or chicken) and subsistence.

In recent years, production of pond-raised tilapia in northern Thailand has been hampered by climate-related risks including extreme temperatures (hot and cold), excessive rainfall, prolonged cloud cover, flood and drought all of which potentially cause fish deaths, stress and reduced feeding and growth rates. In order to better understand the effects of climate on tilapia pond farms 
this study compared sites along an elevation gradient in northern Thailand. The specific objective of this study was to improve understanding of how fish farmers in different elevation perceive and respond to climate impacts. The differences among sites at higher and lower elevation provided insights into the kind of changes in risks farmers may face as climate changes that could be helpful in developing adaptation strategies for individual farmers and the sector as a whole.

\section{Material and Methods}

\subsection{Sampling of Fish Farms}

A total of 585 fish farmers were interviewed for this study. The tilapia farmers were randomly selected from the list of farmers in collaboration with the fisheries officers of the Department of Fisheries. An effort was made to interview fish farmers currently or recently having reared tilapia in fish ponds in nine provinces in northern part of Thailand. Not all who had recently stopped farming could be contacted. Local fisheries officials, community leaders and private sector feed and stock suppliers were used to help locate farmers. Almost all farmers approached agreed to participate in the survey and were able to answer all questions. Interviews were carried out using a structured questionnaire with farmers. The questionnaire covered individual, farm and site level characteristics as well as more detailed sections about impacts from extreme temperatures (hot and cold), excessive rainfall, prolonged cloud cover, flood and drought.

Sites were grouped by provinces into four elevations for analysis: <100 meters above sea level (masl) (Nakhonsawan, Pichit, Kamphengphet, Uttaradit and Phitsanulok), 100 - 300 masl (Lampang), and 300 - 500 masl (Phayao and Chiangrai) and >500 masl (upland areas in Chiangmai). The characteristic climate of each elevation are described and summarized in Table 1.

\subsection{Data Analysis}

The data were compared between elevations for each fish farm. All reports about difference in this text were significant at the $\mathrm{P}<0.05$ or better level; Tukey HSD tests were used post-hoc to separate means following detection of a significant main effect in ANOVA when there was three or more means.

\section{Results and Discussion}

\subsection{Characteristics of Fish Farmers}

The characteristic of the farms and farmers' obtained from the present study are presented in Table 2 . The results show that there were more male farmers than females. Fish farmers were mostly middle-age and had a primary school level of education. Approximately 30\% of households had a monthly income in the range of 5,000 - 10,000 Thai Baht. The fish farmers' commonly had pond-culture experience ranged from 3 - 10 years.

\subsection{Climate Impacts at Different Elevation}

The likelihood of climate impacts on farms in different range of elevation (masl) is shown in Figure 1. Fish farms at different elevations reported different climate and weather-related impacts. In the area where elevation above sea level is $<100 \mathrm{~m}$, farms were affected more by floods (36\%) and extreme hot weather (31\%). Farms at elevation above sea level 100 - 300 had higher drought (35\%) problem than other areas. The highest long cloud cover (51\%) impact was found in 300 - 500 sites. On the other hand, fish farmers in the area where elevation above sea level is $>500$ were impacted most by extreme cold weather.

Table 1. Climate in the four study areas (between years 1990-2010). Provinces for which precipitation and temperature data are shown below are underlined.

\begin{tabular}{|c|c|c|c|c|}
\hline \multirow{2}{*}{ Conditions } & \multicolumn{4}{|c|}{ Elevation MASL (m) } \\
\hline & $<100$ & $100-300$ & $300-500$ & $>500$ \\
\hline Provinces & Nakon-swan Kamphengphet Phitsanolok Uttaradit & Lampang & Phayao Chiangrai & Chiangmai \\
\hline Mean minimum temp in coldest month & 18.6 (Jan) & 15.7 (Jan) & 13.3 (Jan) & 12.6 (Dec) \\
\hline Mean maximum temp in coldest month & 37.6 (Apr) & 37.9 (Apr) & 35.4 (Apr) & 27.4 (Apr) \\
\hline Mean precipitation in wettest month & 250.2 (Sep) & 218.6 (Sep) & 281.2 (Sep) & 186.8 (Sep) \\
\hline Mean precipitation in driest month & $4.4(\mathrm{Jan})$ & 3.9 (Jan) & $7.4(\mathrm{Jan})$ & $3.3(\mathrm{Jan})$ \\
\hline Average mean annual precipitation (mm) & 1289.4 & 900.3 & 1398.9 & 1233 \\
\hline
\end{tabular}


Table 2. Selected demographic characteristics of the fish farmers $(n=585)$.

\begin{tabular}{|c|c|c|c|}
\hline Characteristic & Percentage & Characteristic & Percentage \\
\hline Age in years & & Education & \\
\hline$<=30$ & 3.6 & No formal & 4.5 \\
\hline $31-44$ & 15.7 & Primary & 60.2 \\
\hline $45-57$ & 42.7 & Lower Secondary & 12.6 \\
\hline $58-71$ & 30.8 & Upper Secondary & 11.8 \\
\hline \multirow[t]{2}{*}{$72+$} & 7.2 & University & 3.8 \\
\hline & & Gender & \\
\hline \multirow[t]{2}{*}{ Household average monthly income (Thai Baht) } & & Male & 55.9 \\
\hline & & Female & 44.1 \\
\hline$<5000$ & 12.8 & Pond-culture experience (yrs) & \\
\hline $5000-9999$ & 30.3 & $<=2$ & 7 \\
\hline 10000 - 14999 & 19.3 & $3-10$ & 62.6 \\
\hline 15000 - 19999 & 9.9 & $11-20$ & 19.0 \\
\hline 20000 - 29999 & 12.8 & $21-29$ & 9.2 \\
\hline $30000+$ & 14.5 & $30+$ & 2.2 \\
\hline
\end{tabular}

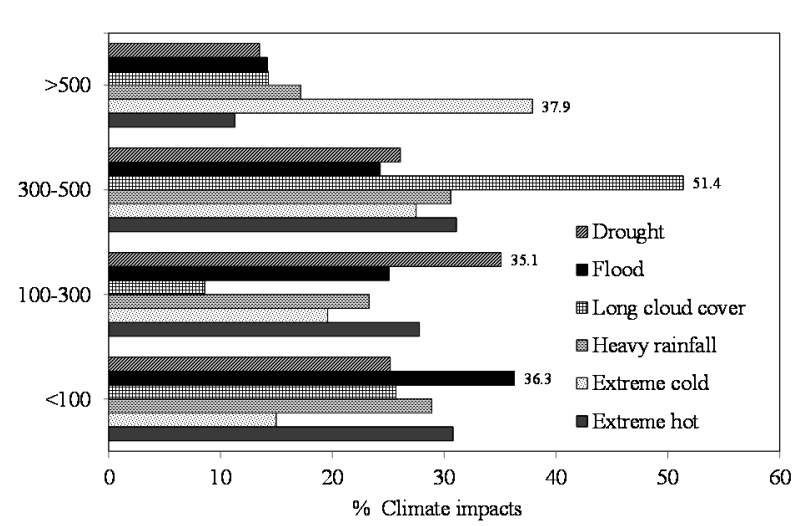

Figure 1. Percentage of climate impacts in different range of elevation above sea level.

\subsection{Effects of Elevation on Culture Type, Purpose of Culture and Farm Size}

Most farmers in northern Thailand cultured tilapia for consumption (94\% of total 585) and many cultured multiple fish species in ponds (Figure 2(b)). About $47 \%$ of farmers cultured tilapia fish for sale. Commercial farms were most common at 300-500 masl sites and these sites also had higher farm size (4+ ponds) than other elevation sites (Figure 2(a) and (b)).

\subsection{Perception of Non-Climate-Related and Indirectly-Related Risks}

In present study, we explored the concern of fish farmers

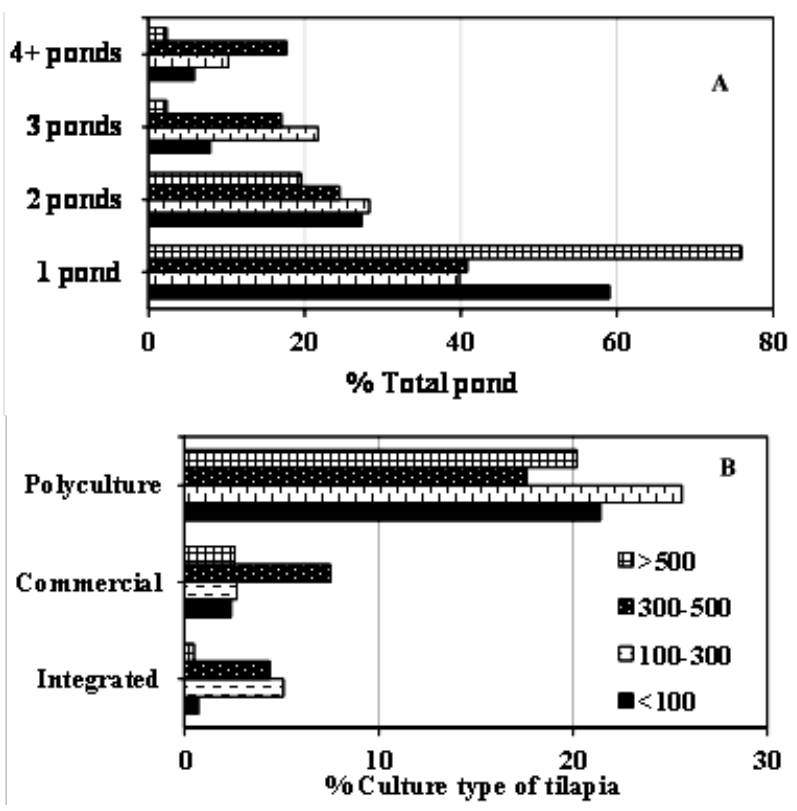

Figure 2. Percentage of farm size (total ponds) and culture type of tilapia fish in different range of elevation above sea level.

about various risk such as disease outbreak, fish theft, poor feed and fingerling quality, and feed prices. Patterns of association with elevation varied among risk types. Fish farmers were most concerned about risks to profitability from low quality fingerlings in all elevation area (Figure 3). Disease outbreak was of comparatively less 


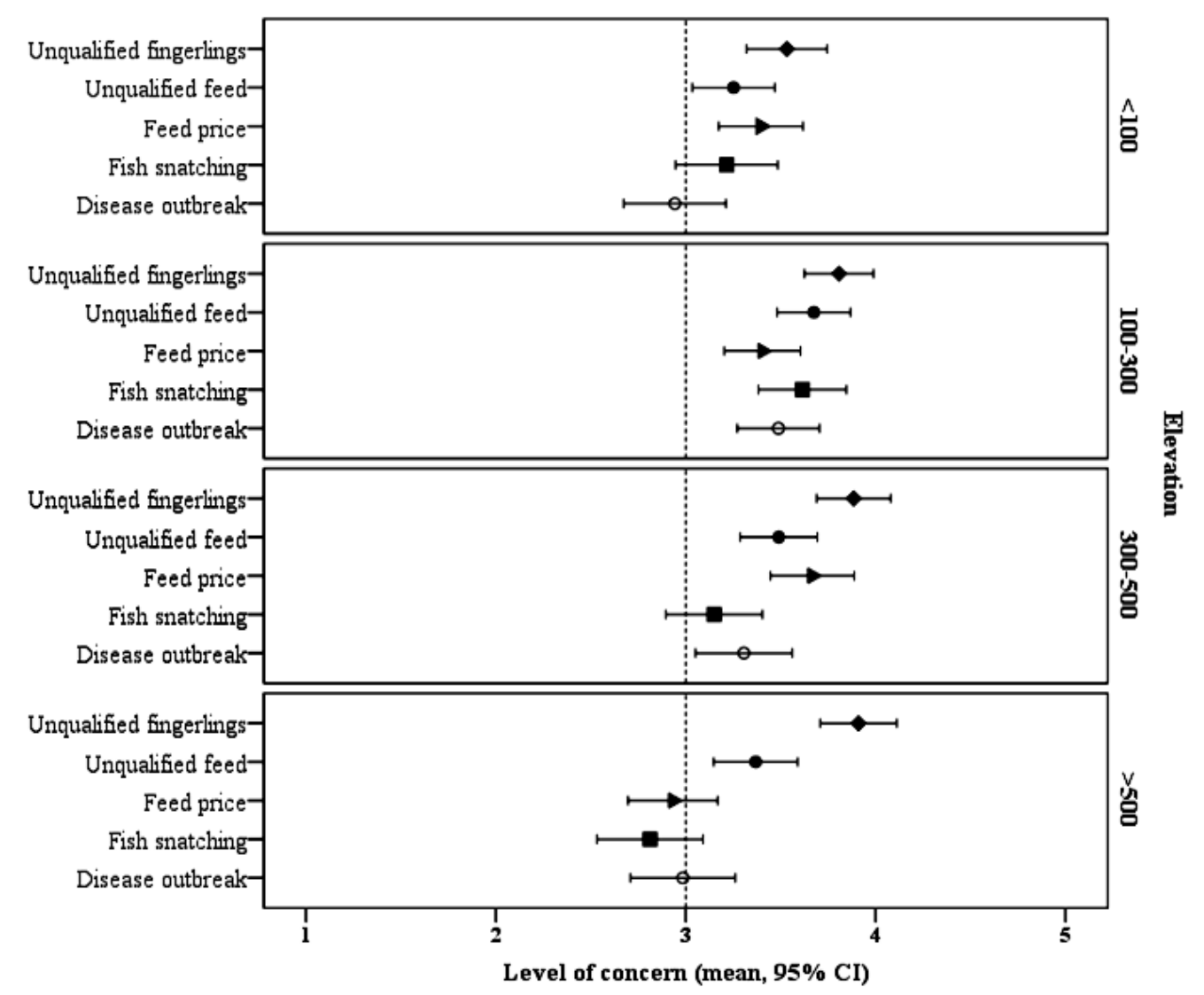

Figure 3. Level of concern of fish pond farmers over five types of non-climate-related and indirectly-related risks in four elevations in northern Thailand. Concern was scored on a scale of 1 (not concerned) to 5 (very concerned). Plotted are means and $95 \%$ confidence intervals for the means.

concern relative to other risks in the area where elevation above sea level is $<100$ masl and $>500$ masl. Concern with feed price and fish theft were lower at the $>500$ masl elevation site than in other three sites $(p<0.05$, Tukey's HSD after ANOVA) conversely fish farmers at 300 - 500 masl had highest level of concern about feed prices.

\section{Discussion}

Aquatic systems in which animals are reared are directly influenced by climate. Climate-related risks increase production costs by making it harder to manage the farm efficiently and as a result of direct production losses [9]. The climate data from Table 1 indicated that there were variations in temperatures among sites at different elevations as would be expected. Air and water temperature are generally cooler at higher elevations [10] and the temperature of the water is regulated mainly by the temperature of the surrounding air. The importance of different climate-related risks to pond aquaculture varied with elevation. As elevation increases (>500 masl), mostly tilapia fish farmers face the extreme cold weather impact which resulted in reduced feeding and growth due to the negative effects on the rate of metabolism, chemical reaction and oxygen consumption [11]. Temperature is one of the most important environmental factors with the greatest influence on the growth performance of animals [12]. Hamdan and colleagues [1] reported that the significant association between production loss and the decrease and increase of water temperature indicating that climate indicators especially temperature is most influential in the aquaculture production. Water temperature affects the quantity of oxygen dissolved in the water, evaporation and aquaculture productivity directly [13]. The aquaculture species are growing dynamically in the minimum and maximum tolerance limit of temperature and survive in optimal temperature. Although tilapia fish has proven popular for its ease of culture, robustness, palatability and tolerance of a range of environmental conditions [5] but these fish do not grow well at temperature below $16^{\circ} \mathrm{C}$ and cannot usually survive for more than a few days below $10^{\circ} \mathrm{C}$ [14]. Watanabe [15] reported $25^{\circ} \mathrm{C}$ to be the optimum temperature for nutrient digestibility in tilapia, O. niloticus (L.) and the optimum temperature for feeding, growth and reproduction is between $26^{\circ} \mathrm{C}$ and $30^{\circ} \mathrm{C}$ [16]. Additionally, the highest 
percentage of small farm size (one pond) was also found in this elevation ( $>500$ masl) one reason possible because of the unsuitable temperature for culture tilapia fish.

O. niloticus is known to tolerate high temperatures: up to $40^{\circ} \mathrm{C}-42^{\circ} \mathrm{C}$ [17]. However, rapid temperature variation will have a negative effect on these species growth due to the less dissolved oxygen in the warm water [12]. The present study clearly showed that farmers growing fish above sea level, $<100$ and 300 - 500 masl, were affected more by extreme hot weather than other areas. Especially, farms at 300 - 500 elevation sites which are in the highest commercial categories, and the larger farm sizes (4+ ponds) are usually found in this elevation, the farmers should be more aware of this important risk because the association between high temperature and dissolved oxygen (DO) have impact on fish production. In addition, the temperatures above $32^{\circ} \mathrm{C}$ may significantly results in slow growth, reduce feeding efficiency and increase mortality [12].

Floods are seasonal phenomena happening frequently during rainy season in certain regions [13]. In 2011, many areas in Thailand had severe flooding leading to highest ever damage costs [18]. The present study clearly showed that the fish farmers at elevation $<100$ masl (Nakonswan, Phijit, Kamphengphet, Phitsanolok and Uttaradit) faced higher impact from floods than in other regions. According to the flood, many farmers have to leave their houses, farms, and lose their job therefore most farms in this site are smaller (one pond) and were mostly subsistence culture. For reduction and adapting to this impact, some farmers who cultured tilapia in these areas changed to culture other fish species for example Mekong giant catfish (Pangasianodon gigas) or used the bigger fingering to reduce time of culture per crop. This strategy will help them minimize the production loss and ensure that the percentage of new fish stock rises successfully and survive in the massive raining season that occurs at year end. Generally, the impact of drought or amount of precipitation (Table 1) has been associated with the volume of water for exchange during culture. The long drought season and raining fluctuation implicated less DO problem to the pond water [1]. In this study, the impacts from drought were mostly founded at 100 - 300 masl where highest percentage of poly culture system has been carried out.

Finally, levels of concern on non-climate risks are associated between elevation and culture type of fish. It was found that the unqualified fingering and feed prices implicated more concerned to culture tilapia fish, especially at the large commercial tilapia culture of northern Thailand (at 300 - 500 masl, Phayao and Chiangrai provinces). To reduce or solve this problem, research in genetics and selective breeding will be needed to improve production efficiency.

\section{Conclusions}

This study showed that the climate-related events and phenomenon (flood, drought, long cloud cover, and extreme hot and cold weather) to tilapia pond culture varies with elevation and culture systems. The extreme cold weather are mostly presented at $>500$ masl elevation where the highest percentage of small farm size (one pond) was found. On the other hand, the fish farmers at $<100$ masl elevation (Nakonswan, Phijit, Kamphengphet, Phitsanolok and Uttaradit) faced higher impact from flooding than in other regions. Moreover, the data from our quantitative survey indicated that low quality fingerings and high feed price are factors of high concern to tilapia farmers, especially at the large commercial tilapia culture of northern Thailand (at 300 - 500 masl, Phayao and Chiangrai provinces). The findings of our survey improve understanding of how fish farmers at different elevation obtain the climate impacts that could be helpful in developing adaptation strategies for individual farmers and the sector as a whole. Future work should focus on how farmers manage risks and awareness of climate change.

\section{Acknowledgements}

The work was carried out with the aid of a grant from the International Development Research Centre, Ottawa, Canada, as a contribution to the AQUADAPT project. Thanks to the many field assistants, students, officials and farmers who helped with the surveys.

\section{REFERENCES}

[1] R. Hamdan, F. Kari and A. Othman, "Climate Variability and Socioeconomic Vulnerability of Aquaculture Farmers in Malaysia," Proceeding of the 2011 International Conference on Business and Economics Research, Singapore, 2011, pp. 47-52.

[2] P. J. Britz, T. Hecht and S. Mangold, "Effect of Temperature on Growth, Feed Consumption and Nutritional Indices of Haliotis midae Fed a Formulated Diet," Aquaculture, Vol. 152, 1997, pp. 191-203. http://dx.doi.org/10.1016/S0044-8486(97)00002-1

[3] P. A. Azevedo, C. Y. Cho, S. Leeson and D. P. Bureau, "Effects of Feeding Level and Water Temperature on Growth, Nutrient and Energy Utilization and Waste Outputs of Rainbow Trout (Oncorhynchus mykiss)," Aquatic Living Resources, Vol. 11, No. 4, 1998, pp. 227-238. http://dx.doi.org/10.1016/S0990-7440(98)89005-0

[4] IPCC, “Climate Change 2001: Thescientific Basis,” Cambridge University Press, Oxford, 2001.

[5] B. Belton, D. Turongruang, R. Bhujel and D. C. Little, "The History, Status, and Future Prospects of Monosex Tilapia Culture in Thailand,” Aquaculture Asia Magazine, Vol. 16, 2009, pp. 16-19.

[6] A. V. Badyaev and C. K. Ghalambor, "Evolution of Life 
History along Elevation Gradients: Trade-Off between Parental Care and Fecundity,” Ecology, Vol. 82, No. 10, 2001, pp. 2948-2960.

http://dx.doi.org/10.1890/0012-9658(2001)082[2948:EO LHAE]2.0.CO;2

[7] P. Lebel, S. Leudpasuk, L. Lebel and P. Chaibu, "Fish Cage Culture in Upper Part of Ping River,” Journal of Fisheries Technology, Vol. 1, No. 2, 2007, pp. 160-170.

[8] P. Lebel, P. Chaibu and L. Lebel, "Women Farm Fish: Gender and Commercial Fish Cage Culture on the Upper Ping River, Northern Thailand," Gender, Technology and Development, Vol. 13, No. 2, 2009, pp. 199-224. http://dx.doi.org/10.1177/097185241001300202

[9] V. T. Sulit, M. E. T. Aldon, I. T. Tendencia, A. M. J. Ortiz, S. B Alayon and A. S. Ledesma, "Regional Technical Consultation on the Aquaculture of P. vannamei and other Exotic Shrimps in Southeast Asia. Manila, Philippines,” Aquaculture Department, Southeast Asian Fisheries Development Center, 2005.

[10] C. L. Meays, "Elevation, Thermal Environment, and Stream Temperatures on Headwater Streams in Northeastern Oregon” Master Thesis, Oregon State University, 2000.

[11] J. H. Tidwell, S. Coyle, C. Weibel and J. Evans, "Effects and Interactions of Stocking Density and Added Substrate on Production and Population Structure of Freshwater Prawns Macrobrachium rosenbergii," Journal of the World Aquaculture Society, Vol. 30, 1999, pp. 174-179. http://dx.doi.org/10.1111/j.1749-7345.1999.tb00864.x

[12] N. P. Pandit and M. Nakamura, "Effect of High Temperature on Survival, Growth and Feed Conversion Ratio of Nile Tilapia, Oreochromis Niloticus,” Our Nature, Vol. 8, 2010, pp. 219-224.

[13] M. N. Kutty, "Site Selection for Aquaculture: Climatic Factors,” 1987.

http://www.fao.org/docrep/field/003/AC171E/AC171E00 .HTM

[14] J. Chervinski, "Environmental Physiology of Tilapias," Proceeding of the Biology and Culture of Tilapia, ICLARM Conference, Manila, Philippines, 1982.

[15] T. Watanabe, T. Takeuchi, S. Satoh and V. Kiron, "Digestible Crude Protein Contents in Various Feedstuffs Determined with Four Freshwater Fish Species," Fisheries Science, Vol. 62, 1996, pp. 278-282.

[16] W. J. Hauser, “Temperature Requirement of Tilapia,” California Fish and Game, Vol. 63, No. 4, 1977, pp. 228233.

[17] J. C. Philippart and J. C. Ruwet, "Ecology and Distribution of Tilapias," In: R. S. V. Pullin \& R. H. LoweMcConnell, Eds., The Biology and Culture of Tilapias, ICLARM, Manila, Philippines, 1982, pp. 15-60.

[18] HAII, “2011 Thailand Flood Executive Summary,” 2012. http://www.thaiwater.net/web/index.php/ourworks2554/3 79-2011flood-summary.html 